\title{
A LÓGICA NO ORDO DISCIPLINAE DE TOMÁS DE AQUINO
}

\author{
LOGIC IN THE ORDO DISCIPLINAE OF THOMAS AQUINAS
}

Lucas Lagasse Corrêa*

\begin{abstract}
RESUMO
O presente artigo visa analisar o conceito de lógica, e situá-la na sua relação com as demais arte-ciências, em textos específicos de duas obras de Tomás de Aquino: Comentário ao De Trinitate de Boécio e Comentário aos Analíticos Posteriores de Aristóteles. Essa proposta surge como exigência para melhor compreender o mesmo Comentário ao De Trinitate, no qual trata, nas Questões 5 e 6, do objeto e do modo de proceder da física, da matemática e da metafísica. As noções de arte e ciência serão aprofundadas enquanto virtudes intelectuais teóricas, para em seguida se definir o que seja a Lógica, seu objeto de estudo e propriedades. Por consequência, tratar-se-á de temas imbricados à mesma lógica, tais como o modo como conhecemos as coisas (epistemologia), a verdade e a ordem das disciplinas. O Comentário ao De Trinitate pertence à primeira temporada do magistério de Tomás em Paris (1252-59), bem antes de seus comentários às obras Aristotélicas (1266-73), as quais demonstram sua maturidade filosófica e teológica. Isto se diz haja vista um desenvolvimento do conceito de lógica ao longo da construção da obra do Aquinate, ou ao menos é possível ressaltar as formas distintas de abordagem do mesmo conceito.
\end{abstract}

PALAVRAS-CHAVE: Lógica. Arte. Ciência. Conhecimento. Ordem das disciplinas.

\section{ABSTRACT}

The present article aims to analyze the concept of logic, and to situate it in its relation with the other art-sciences, in specific texts of two works by Thomas Aquinas: Commentary to Boethii De Trinitate and Commentary to Aristotle Analytica Posteriora. This proposal arises as a requirement to better understand the same Commentary to De Trinitate, in which it deals, in Questions 5 and 6, with the object and the way of proceeding in physics, mathematics and metaphysics. The notions of art and science will be deepened as theoretical intellectual virtues, to then define what logic is, its object of study and properties. Consequently, the same logic will be involved in themes, such as the way we know things (epistemology), the truth and the order of the disciplines.

KEY WORDS: Logic. Art. Science. Knowledge. Order of disciplines.

\footnotetext{
* Mestre em Filosofia pelo PPG-FIL/UFES. Professor na Secretaria Estadual de Educação do Espírito Santo (SEDU). E-mail: lucaslagasse20@gmail.com
} 


\section{INTRODUÇÃO}

O Comentário de Tomás de Aquino ao De Trinitate de Boécio pertence à primeira temporada do magistério daquele em Paris (1252-59), bem antes de seus comentários às obras Aristotélicas (1266-73), as quais demonstram sua maturidade filosófica e teológica. Isto se diz haja vista um desenvolvimento do conceito de lógica ao longo da construção da obra do Aquinate, ou ao menos é possível ressaltar as formas distintas de abordagem do mesmo conceito.

Na Questão 5, artigo 1 da supracitada obra, o Aquinate cita Agostinho de Hipona para dizer que a não inclusão da Lógica na clássica tríplice divisão das ciências especulativas (física, matemática e metafísica) demonstra que essa mesma divisão está equivocada. Esta citação nomeia a lógica como "filosofia racional”, e, assim, ela estaria contida na filosofia especulativa. Tem-se, então, pela primeira vez - ao menos nos artigos 5 e 6, objetos de nosso artigo - a inserção da lógica na discussão dos objetos das ciências teóricas.

Na Questão 6 da mesma obra, Tomás de Aquino (1999) trata do modo de proceder das ciências especulativas - raciocinativamente, disciplinativamente e intelectivamente - e isso implica, no artigo 1, um certo entrelaçamento entre o modo de proceder da filosofia natural (física) e da racional (lógica). Nesse mesmo artigo são tratados os dois clássicos modos de se proceder raciocinativamente: a argumentação dos 1) efeitos às causas e a das 2) causas aos efeitos. No mesmo artigo 1, segunda parte, ao tratar da matemática, ele insere uma atividade da lógica que é própria de todas as ciências, e que é tratada também e principalmente nos Analíticos posteriores: a demonstração. E por fim, no mesmo artigo 1, terceira parte, tem-se a questão do proceder intelectivamente para compreender a metafísica: o Aquinate difere as operações da razão em que o intelecto se refere aos princípios e a ciência, às conclusões.

Toda essa Questão é respondida com uma certa divisão da lógica em graus de certeza, os quais trataremos no decorrer deste texto. Nessa mesma Questão 6 tem-se em estágio inicial os princípios de várias doutrinas expostas no Comentário aos Analíticos Posteriores, tais como a divisão da lógica em graus de certeza, aludida acima, os tipos de argumentação, as vias de resolução e composição, e uma ordem nas disciplinas (não explícita numa lista, mas entendida com o transcurso da argumentação e que se faz necessário organizar melhor, haja vista a extensão e o objetivo outro das Questões 5 e 6).

No Proêmio do Comentário aos Analíticos Posteriores, Tomás de Aquino fala da necessidade de uma "arte que dirija o mesmo ato da razão, para que o homem proceda 
ordenadamente, facilmente e sem erro nesse ato. E essa arte é a lógica, quer dizer, a ciência racional". Esse texto, ao longo do desenvolvimento da Escola Tomista, foi analisado e entendido de formas distintas, e nos valeremos do comentário de Álvaro Calderón (2011) para sedimentar melhor o entrelaçamento dessas duas virtudes intelectuais distintas - a arte e a ciência.

Os temas que surgirem no decorrer da análise dos textos — conhecimento, verdade, virtudes, ordem das disciplinas, etc. - serão tratados detidamente, portanto sejam necessários para a compreensão da mesma análise.

\section{A LÓGICA NO ELENCO DAS DISCIPLINAS TEORÉTICAS}

Na Questão 5, artigo 1, $1^{\text {a }}$ objeção, do Comentário de Tomás de Aquino ao De Trinitate de Boécio, o Aquinate faz a seguinte citação: “Ademais, Agostinho diz no livro VIII de A cidade de Deus que a filosofia racional, que é a lógica, está contida sob a filosofia contemplativa ou especulativa. Portanto, como não faz menção dela, parece que a divisão é insuficiente”. Com isso, Tomás de Aquino dá a entender que não incluir a lógica na clássica tríplice divisão das ciências especulativas (física, matemática e metafísica) demonstra que essa mesma divisão está equivocada pois, se a lógica é racional, deveria estar junto das mesmas ciências especulativas.

\subsection{Filosofia racional e instrumento das ciências}

Ao responder essa objeção, o Aquinate, baseado na Metafísica de Aristóteles, assevera que as ciências especulativas têm um fim em si mesmas, quer dizer, não operam — ao acrescer conhecimento no ser humano - com uma finalidade exterior ao próprio conhecimento. E aí está uma das diferenças da lógica e das ciências especulativas: "as coisas que a lógica se ocupa não são das que se deseja conhecer por si mesmas, mas como um certo auxílio para as outras ciências"1 (Boetii. Q. 5, art. 1, ad 2). A lógica é entendida pelo Aquinate como aquela que dá às ciências especulativas os instrumentos para que possam operar: "os silogismos, definições e similares" (Boetii. Q. 5, art. 1, ad 2). Sendo assim, ela não é ciência

\footnotetext{
${ }^{1}$ Doravante, ao tomarmos citações do Comentário de Tomás de Aquino ao De Trinitate de Boécio (abreviação: In Boetii), questão 5, artigo 1, resposta para a objeção 2). " $Q$ ” significa "questão"; "art.", artigo; "resp.", resposta; "ad", resposta para uma objeção. A Tradução em português que usamos é a de Carlos Arthur R. do Nascimento, São Paulo, SP: Fundação Editora da UNESP, 1999.
} 
propriamente dita, mas, antes, um instrumento para que as ciências se desenvolvam. Isso é endossado também por Aristóteles, segundo o qual

O modo de proceder da ciência deve ser procurado antes das ciências. O Comentador $^{2}$ diz no mesmo lugar que alguém deve aprender, antes de todas as outras ciências, a lógica, à qual pertence o trívio, e que ensina o modo de proceder de todas as ciências. (Boetii. Q. 5, art. 1, ad 3).

Até então a lógica foi dita e entendida como "filosofia racional" e "instrumento das ciências", mas quando o Aquinate trata da classificação das ciências especulativas em relação ao Trívio (Trivium) (Boetii. Q. 5, art. 1, objeção e resposta 3) ele traz um novo aspecto, o aspecto artístico dela. Ou seja, a lógica não implica somente um conhecimento, mas produz certa obra da razão - "como a construção de um silogismo, formar uma oração" (Boetii. Q. 5, art. 1, ad 3). Note-se a diferença entre as artes e as ciências: estas têm em vista o conhecimento pelo conhecimento, enquanto aquelas implicam uma obra.

\subsection{Modos de proceder das ciências}

Na Questão 6 do Comentário ao De Trinitate de Boécio, o Aquinate se pergunta, no artigo 1, sobre os modos de proceder de cada ciência especulativa: caberia aplicar-se raciocinativamente quanto aos assuntos da física, disciplinativamente aos da matemática e intelectivamente aos da metafísica? É um artigo com três perguntas que são desenvolvidas no mesmo esquema dos artigos (pergunta, objeções, sentido contrário, resposta e resposta às objeções). Há outros três artigos (se se pode usar da imaginação nos assuntos teológicos, se nosso intelecto pode contemplar a forma divina, e caso a resposta desta última seja positiva, se isso se dá por alguma ciência especulativa), mas não correspondem ao intuito da análise que hora se faz, que versará tão somente no primeiro e longo artigo, que trata dos modos de proceder das ciências, não que esses modos sejam exclusivos destas, mas, como se verá, são os mais adequados.

À primeira vista, pode-se ter a impressão de que o assunto esteja distante daquilo que entendemos por lógica. Mas, entendendo o conceito de que esta seja um instrumento das ciências, estudar o modo de proceder destas é fundamentar essa noção de que a lógica seja delas um instrumento (órganon). Isso indica, também, que os modos de proceder das ciências

\footnotetext{
${ }^{2}$ É como ficou conhecido, na literatura escolástica medieval, o filósofo árabe Averróis, devido aos seus esforços e trabalhos filosóficos de comentar a obra do Estagirita.
} 
seguem a regras da lógica em suas bases; mas em momento algum o Aquinate propõe um único modo para todas as ciências, pelo contrário: cada ciência alcança a verdade por algum meio específico e diferente das outras (MAURER in AQUINAS, 1986, p. 21). Ademais, a Questão 6, especialmente o artigo 1, dá outro critério para distinção das ciências do que os seus respectivos objetos ${ }^{3}$ : o modo de proceder de cada uma, que deve se coadunar com seus objetos.

\subsubsection{O modo de proceder da filosofia natural (física)}

O artigo 1 da Questão 6 abre-se questionando se é conveniente aplicar-se raciocinativamente $^{4}$ aos assuntos naturais, quer dizer, da física. Tomás de Aquino elenca algumas objeções contra o uso do raciocínio na ciência física:

1) a filosofia racional (Lógica) e a natural (Física) são distintas, e pertence àquela o proceder raciocinativamente, e não a esta; 2) na Física, Aristóteles distingue os procedimentos em conclusões racionais e físicas, portanto não seria próprio da física proceder raciocinativamente; 3 ) aquele método que é próprio de todas as ciências (aqui ele se refere ao raciocínio) não pode ser dito método de uma só ciência (no caso, a ciência natural ou física); o raciocínio é o método das ciências, e ele pode ser classificado em dois: aqueles que discorrem (do conhecido ao desconhecido) dos efeitos para as causas, e os que discorrem das causas aos efeitos; 4) o modo de proceder racionativo é distinto do científico, segundo o Livro IV da Ética (de Aristóteles). À filosofia natural se atribui o científico, portanto não o raciocinativo.

Em seguida, o Aquinate dá o argumento contrário às objeções anteriores: "a razão se ocupa com as formas dos corpos. Ora, considerar os corpos cabe sobretudo à ciência natural. Logo, atribui-se-lhe convenientemente o proceder raciocinativamente" (Boetii. Q.6, art. 1, sed contra).

Tomás de Aquino, no Respondeo ${ }^{5}$, elenca três modos de dizer pelos quais um procedimento científico é dito raciocinativo:

1) quando se parte dos princípios que são as obras da razão - gênero, espécie, diferença, oposto, etc. - assim se servem as ciências das proposições (predicáveis)

\footnotetext{
${ }^{3}$ A problemática dos objetos (subjectum) de cada ciência é longamente desenvolvida na Questão 5 do De Trinitate.

${ }^{4}$ Tradução de Carlos Arthur R. do Nascimento para o termo latino original rationabiliter". A tradução espanhola de Alfonso García Marqués sugere racionalmente.

${ }^{5}$ Resposta, que é um artigo direto no qual ele dá a resposta final dele, solucionando a questão. Ver Boetii, Q. 6, Resp.
} 
ensinadas pela lógica; logo, não é este o modo de proceder da Física, restando os dois sentidos seguintes para que a física opere raciocinativamente.

2) "a partir do termo no qual se detém no procedimento" (Boetii, Q. 6, Resp.); o termo último de uma investigação racional é a intelecção dos princípios, pelos quais julgamos por resolução: isso é o que se chama demonstração ${ }^{6}$. Pode acontecer de essa investigação racional não alcançar o termo (intelecção dos princípios), e ainda restarem alternativas distintas que produzem opinião, mas não ciência: a isso chama-se Dialética. Esta produz opinião, com base em razões prováveis, enquanto a Lógica produz ciência (certeza), através da resolução aos primeiros princípios do intelecto.

3) a partir do "modo próprio da alma racional [...] conhecer" (Boetii, Q. 6, Resp.) - e só aqui, segundo o Aquinate, é que se pode dizer que o procedimento raciocinativo é próprio da ciência natural (física); pelo texto se expõe algo da teoria tomista do conhecimento:

[...] quanto ao fato de que, assim como a alma racional recebe o conhecimento dos inteligíveis (que são mais conhecidos de acordo com a natureza) a partir dos sensíveis (que são mais conhecidos quanto a nós), também a ciência natural procede a partir do que é mais conhecido quanto a nós e menos conhecido de acordo com a natureza [...] como cabe à razão discorrer de um para o outro, isto se observa sobretudo na ciência natural, onde, a partir do conhecimento de uma coisa, chega-se ao conhecimento de outra [...] (Boetii, Q. 6, Resp.).

A física, ao proceder raciocinativamente, faz demonstrações pelas causas extrínsecas, quer dizer, por causas sensíveis e mais conhecidas a nós, por isso Tomás de Aquino a entende como a ciência que mais está em conformidade com o intelecto humano. Assim, por conta de a física ter um caráter experimental e seu modo de proceder dar ao entendimento humano um verdadeiro conhecimento por causas, assim é seu modo próprio de proceder o chamado "racionabiliter".

Ao fim dessa primeira pergunta dentro do artigo 1, o pensador italiano responde àquelas quatro (4) objeções iniciais:

1) este argumento toma o processo raciocinativo do primeiro modo (explicado no Respondeo), o que de fato não se aplica à filosofia natural (Física), mas tão somente à mesma filosofia racional (Lógica) e à Metafísica; 2) o processo raciocinativo aqui abordado é o do segundo modo (elencado no Respondeo), por isso, também, não se aplica à Filosofia natural

\footnotetext{
${ }^{6} \mathrm{Na}$ demonstração, própria da terceira operação do intelecto, há três coisas: a causa do efeito, quer dizer, o princípio, a paixão (que alguns traduzem por atributo ou propriedade) que está no sujeito, e o mesmo sujeito. Ver II Post. Analit. L. I, lect. 2, n.5.
} 
(Física); 3) em todas as ciências, resultado da demonstração, se procede de um (conhecido) para outro (desconhecido) de acordo com noções, não de uma coisa (objeto real e concreto) para outra, isto é próprio da filosofia natural; 4) seguindo ainda a resolução do Respondeo, o procedimento raciocinativo do primeiro caso cabe à ciência racional $^{7}$, o segundo caso à ciência moral (ética, economia e política), e o terceiro, à ciência natural (física).

\subsubsection{O modo de proceder da matemática}

Na segunda parte do artigo 1 da Questão 6, pergunta o Aquinate se é conveniente aplicar-se disciplinativamente ${ }^{8}$ aos assuntos matemáticos. As objeções a essa aplicação são as seguintes:

1) disciplina é a recepção da ciência; ora, em qualquer parte da filosofia se recebe ciência, pois todas as partes desta usam de processos demonstrativos. Logo, não é exclusividade da matemática proceder disciplinativamente; 2) o modo de proceder diciplinativamente pertence mais ao filósofo natural do que ao matemático, pois os assuntos naturais são mais certos, logo mais fáceis de se aprenderem e de se ter disciplina deles (uma vez que têm, como dito na parte anterior do mesmo artigo 1, matéria em sua composição); 3) o começo de uma ciência é o que a torna mais fácil sua disciplina. O começo de todas as ciências se dá pela Lógica, antes da matemática e das outras ciências, por exemplo. Então pertence à Lógica proceder disciplinativamente; 4) o modo de proceder da ciência natural (Física) e da divina (Metafísica ou Teologia) é tomado das potências da alma (razão e intelecto). Assim também deve ser o da matemática. Logo, não seria adequado que a matemática seja disciplinativamente.

Os argumentos em sentido contrário (sed contra) às objeções iniciais são:

1) "proceder disciplinativamente é proceder demonstrativamente através da certeza" (Boetii, Q. 6, Sed contra). E citando o Almagesto ${ }^{9}$, a matemática usa das demonstrações, e, portanto, seu proceder próprio é disciplinativamente; 2) em várias passagens o Filósofo ${ }^{10}$ chama as ciências matemáticas de disciplinas.

\footnotetext{
${ }^{7}$ Aqui o Aquinate põe como sinônimos ciência e filosofia.

8 A tradução espanhola, de A. G. Marqués, usa "disciplinarmente" ou "por aprendizagem” para o "disciplinabiliter" do original latino; a tradução inglesa, de A. Maurer, usa "mode of learning”, ou seja, "modo de aprender". Mais à frente o Aquinate dará uma definição do que seja aprender (receber ciência de outrem).

${ }^{9}$ Tratado matemático e astronômico escrito por Ptolomeu, no século II d.C.

${ }^{10}$ É como Tomás de Aquino nomeia Aristóteles.
} 
Passa-se, agora, a analisar o Respondeo, a solução para a pergunta. O Aquinate afirma que não é só a matemática que procede disciplinativamente, quer dizer, que é transmitida através do ensino, mas assim proceder é o mais adequado. Ele dá uma definição do que é aprender: "receber a ciência de outrem" (Boetii, Q. 6, Resp.), para dizer que se chama processo disciplinativo todo aquele que conduz à ciência, coisa que a matemática o faz.

Tomás de Aquino diz ser a matemática mais certa que a ciência natural e a divina, uma vez que esta está desligada em suas considerações do movimento e da matéria — necessária para todo conhecimento humano —, e aquela situa-se demasiadamente na matéria e no movimento. Como a consideração da física depende de muitas coisas - matéria e forma, disposições materiais e propriedades decorrentes da forma, por exemplo - o seu conhecimento é mais difícil. Prossegue nessa linha, argumentando que:

[...] quanto mais uma ciência se aproxima dos singulares, como as ciências operativas (como a medicina, a alquimia e a moral), menos podem ter de certeza por causa da multidão do que precisa ser considerado em tais ciências (a omissão de não importa o que acarreta um erro) e por causa da variabilidade disso. (Boetii, Q. 6, Resp.).

A matemática é mais certa que a ciência divina, pois esta é a mais afastada do sensível, e é pelo sensível que o conhecimento humano tem início. Como a matemática "apresenta-se ao sentido e está subordinada à imaginação, como a figura, a linha, o número e similares" (Boetii, Q. 6, Resp.), o intelecto humano, que como dito anteriormente, ao conhecer, depende das espécies inteligíveis (provenientes das imagens sensíveis ou fantasmas), tem mais facilidade de compreender a mesma matemática, mais do que conhecer a quididade (essência) da substância, do ato, da potência.

O modo da matemática tem um "caráter dedutivo, com apoio na imaginação" (MAURER, in AQUINAS, 1986, p. 58), quer dizer, as demonstrações matemáticas partem de princípios e definições, e suas conclusões são deduzidas, por consequência, daqueles princípios mesmos, pela causalidade formal; ademais, diferentemente da física, a matemática não se utiliza das causas final e eficiente para suas demonstrações (MAURER, in AQUINAS, 1986, p. 35).

Observa-se que o nome "matemática" vem do grego, mathein, significa ensinar. O sinônimo latino é discere, donde vem disciplinabiliter, disciplina (MAURER, in AQUINAS, 1986, p. 36). O nome dessa ciência indica seu mesmo modo de proceder, a Via Disciplinae (Via da Disciplina) - tratada e distinguida da Via Compositionis (Via da Composição) na 
terceira parte do artigo 1 da Questão 6. A matemática é aquela "ciência em estado perfeito: fundamentada, organizada e em estado de ser ensinada" (MAURER, in AQUINAS, 1986, p. 59). Contudo, essa Via da Disciplina se entrelaça perfeitamente com a Via da Composição, haja vista que aos resultados das demonstrações matemáticas se arrolam outros mais, formando assim um corpo científico, e se chegando a novos conhecimentos. Noutras palavras, o Aquinate assevera que o característico próprio do modo de proceder da matemática é diciplinativamente (disciplinabiliter), que pode ser compreendido por dedutivo ou por aprendizado.

Em resposta às objeções iniciais, argumenta Tomás de Aquino:

1) mesmo que todas as ciências tenham o método disciplinativo, é na matemática que isso se dá mais fácil e certamente; 2) a matemática tem por objeto o ente segundo a quantidade, ou seja, um ente que depende da matéria sensível para ser (ou ao menos de um acidente desta, a categoria quantidade, como dito). Isto posto, ela se apresenta pelos sentidos e imaginação à razão. A Física também está ligada aos sentidos, à matéria, mas por conta da mutabilidade de seus objetos - ela investiga o ente enquanto móvel — sua certeza é menor do que a da matemática; 3) foi dito que o aprendizado se inicia pelo mais fácil. Ora, pode ser que nem sempre o início seja fácil: começa-se o aprendizado pela Lógica, mas esta tem uma dificuldade máxima, já que seu objeto são os entes de razão, mas mesmo assim começa-se com ela, pois as outras ciências dela dependem para proceder; 4) "[...] o modo de proceder das ciências é tirado das potências da alma por causa do modo de proceder de que são dotadas as potências da alma na ação" (Boetii, Q. 6, ad 4), ou seja, os métodos das ciências têm correlação direta com os modos pelos quais as potências da alma podem proceder; e essas potências da alma se diversificam de acordo com os objetos (exteriores ou interiores). O modo de proceder da Física é proveniente da razão; o da Metafísica provém do intelecto (como será visto mais adiante); e o da Matemática também provém da razão, uma vez que esta recebe da imaginação seus objetos.

\subsubsection{O modo de proceder da metafísica}

A terceira pergunta e parte do artigo 1 da Questão 6 indaga se é conveniente proceder intelectivamente quanto à ciência divina. Consigna-se que, na Questão 6, quando Tomás de Aquino trata de "ciência divina" ora se refere à teologia revelada (Teologia Sagrada), ora à 
teologia natural (Metafísica); portanto deve-se precisar a referência através do contexto da argumentação.

As objeções ao proceder intelectivamente são as seguintes:

1) proceder intelectivamente é próprio para se reduzir aos princípios, enquanto a ciência chega às conclusões. A ciência divina chega às conclusões, na maioria das vezes em seu procedimento; por isso proceder intelectivamente não é próprio dessa ciência; 2) as coisas divinas excedem o intelecto humano, por isso essa ciência não pode proceder de modo intelectivo; 3) o conhecimento angélico não depende dos sentidos — são puros espíritos - ou das coisas compostas, diferentemente do conhecimento humano - que depende destes. Por isso essa não pode proceder intelectivamente; 4) a teologia (revelada) ocupa-se da fé, cujo fim é o inteligir. Por isso, não se pode dizer que "aplicar-se intelectivamente acerca do divino é o modo de proceder da teologia, mas o fim" (Boetii, Q. 6, art. 1, obj. 4 ( $3^{\text {a }}$ parte)).

No sentido contrário, argumenta-se em defesa de que essa ciência, a divina, ou teologia, procede intelectivamente:

1) “o intelecto se ocupa dos espíritos criados e a inteligência do próprio Deus" (Boetii, Q. 6, art. 1, sed contra ( $3^{\mathrm{a}}$ parte)), como a ciência divina trata desses assuntos, ela procede intelectivamente; 2) "o modo de proceder da ciência deve corresponder à matéria", as coisas divinas são inteligíveis, então proceder intelectivamente é próprio da ciência divina.

A Resposta que o Aquinate dá é a seguinte:

\begin{abstract}
Assim como se atribui raciocinativamente à filosofia natural porque sobretudo nela se observa o modo da razão, assim também se atribui o proceder intelectivamente à ciência divina porque sobretudo nela se observa o modo do intelecto. Ora, a razão difere do intelecto assim como a multidão da unidade. [...] é próprio da razão estender-se a muitos para deles recolher um conhecimento simples. (Boetii, Q. 6, art. 1 , resp. $\left(3^{\mathrm{a}}\right.$ parte $\left.)\right)$.
\end{abstract}

A razão humana é extensiva, discursiva no tempo e no espaço, passa de uma coisa conhecida a outra desconhecida, diferente e inferior aos anjos, cujo intelecto não depende de sentidos e matéria - eles têm o que se chama intuição intelectual direta da essência das coisas. O intelecto angélico considera primeiro a verdade una e simples das coisas (essência) e depois aplica-a na multidão das coisas - caminho inverso faz a razão humana. Já Deus, “inteligindo sua essência conhece tudo" (Boetii, Q. 6, art. 1, resp. (3 $3^{\mathrm{a}}$ parte)).

A atividade racional do homem pode culminar numa atividade intelectual, chama-se isto de Via da Resolução, quando a razão "recolhe a verdade una e simples a partir de muitos" 
(In Boetii, Q. 6, art. 1, resp. (3 ${ }^{\mathrm{a}}$ parte)), ou seja, se busca a unidade através da multiplicidade das coisas, como quando se procura "a causa ou universal a partir de muitos efeitos ou casos particulares" (MAURER, in AQUINAS, 1986, p. 59). A consideração intelectual também pode se tornar consideração racional, pela Via da Composição ou Invenção, quando “o intelecto abarca a multidão [das coisas] em um [só conceito ou essência]" (MAURER, in AQUINAS, 1986, p. 59), quer dizer, da unidade à multiplicidade das coisas, "das causas aos efeitos, do universal ao particular" (MAURER, in AQUINAS, 1986, p. 59). Assim, o término do raciocínio humano é a consideração intelectual, o proceder intelectivamente.

Todas as ciências, se se considera a Via da Resolução, acabam considerando a ciência divina. A Via da Resolução procede dos efeitos para as causas - diferente da Vida da Composição, que procede das causas aos efeitos. O término da resolução são as causas supremas, simples, universais, que são as substâncias separadas. A ciência divina (metafísica), considerando essa mesma Via da Resolução, tem por término, então, resolver tudo a partir do ente, haja vista que "ente" é o mais universal e simples.

A ciência divina, então, considera "as substâncias separadas e o que é comum a todos os entes" (MAURER, in AQUINAS, 1986, p. 59), por isso o modo de proceder dela é o intelectivo. Dela procede, então, os princípios de todas as outras ciências. Ela pode ser dita "filosofia primeira" pois a consideração intelectual é princípio da racional; e ainda é dita "metafísica" pois é aprendida depois das outras ciências (depois da matemática, da física...), já que a consideração intelectual (ciência divina) é o termo da racional (demais ciências).

Por fim, as respostas às objeções iniciais:

1) dizer que a ciência divina procede intelectivamente não significa dizer que ela não raciocina - quando procede dos princípios às conclusões. Mas seu raciocínio é muito semelhante à consideração intelectual, e suas conclusões aos princípios; 2) Deus está acima dos intelectos criados quanto à compreensão, mas ele se compreende a si mesmo ao se inteligir. Ou seja, nenhum intelecto (humano ou angélico) compreende o que ele é, sua essência, mas nosso intelecto pode conhecer o "se ele é", ou seja, se ele existe - e isto se dá na mesma metafísica; 3 ) quando o homem exerce a consideração intelectual ele se assemelha ao intelecto angélico; 4) o conhecimento da fé pertence sobretudo ao intelecto, visto que não a recebemos por investigação racional, mas por uma Revelação, à qual assentimos intelectualmente. 


\section{A Lógica NO COMENTÁRIO AOS ANALÍticos POSTERIORES DE ARISTÓTELES}

O Proêmio do Comentário aos Analíticos Posteriores de Aristóteles é riquíssimo em definições que fazem melhor compreender o que é a Lógica, segundo Tomás de Aquino.

\section{1 A definição da lógica}

O homem é um ser que vive de artes e de razão (Metafísica I, 980b 27-28). Com esta ele busca conhecer o mundo, sem intervir nele, e para tal há os hábitos ${ }^{11}$ intelectuais especulativos - o intelecto, hábito dos primeiros princípios como, por exemplo, o da não contradição; a sabedoria, hábito das causas primeiras e dos princípios; e a ciência, hábito das demonstrações (STh., I-II, q. 57, a. 2.) ${ }^{12}$; com aquelas (artes), busca o homem produzir e agir no mundo exterior a ele, e então temos outros hábitos intelectuais, os práticos - a arte, reta razão no fazer e a prudência, reta razão no agir (STh., I-II, q. 57, a. 3 e 4). Eis a distinção do homem, o que lhe difere dos outros animais. Estes, para agirem, seguem seus instintos naturais; aquele age dirigido pelo "juízo de sua razão" (Post. Anali.. lib. 1, L. I, n. 1) ${ }^{13}$. A esses hábitos chama-se virtudes intelectuais ${ }^{14}$.

Seguindo rigorosamente essa classificação acima, a Lógica não seria arte, uma vez que “não produz nenhuma obra externa ou artefato" (CALDERÓN, 2011, p. 86), nem seria uma ciência moral — advinda da prudência — já que nessas as ações humanas "procedem da vontade deliberada, pelas quais o homem se volta ao bem e ao mal" (CALDERÓN, 2011, p. 87). A definição de arte que Tomás de Aquino dá no Proêmio é mais ampla, com sentido lato, — diferente da definição estrita da Suma Teológica —, ela é “certa ordenação da razão, de

\footnotetext{
${ }^{11}$ Hábito - qualidade da alma que a predispõe à realização de alguns bens; do ponto de vista metafísico, está entre a potência e o ato; exemplifique-se: radical no ser, em ato, é o hábito da ciência, quando o tenho por uma repetição, em potência enquanto é possível desenvolvê-la, visto que nem todos têm ciência. Há hábitos naturais, como os intelectuais especulativos, e há hábitos adquiridos, como os intelectuais práticos.

${ }^{12}$ STh., abreviação de Suma Teológica, nas citações, doravante.

${ }^{13}$ Post Anali. É abreviação do Comentário aos Analíticos Posteriores de Aristóteles.

${ }^{14}$ Note-se que hábito aqui é tomado como qualidade da alma (STh., I-II, q. 49, a. 1) que a dispõe bem ou mal com sua natureza e finalidade; se a disposição for boa, chama-se virtude, se má, vício. Virtude é, portanto, um hábito operativo, psíquico, da alma; esta tem suas potências (intelecto e vontade), que são atualizadas pelos hábitos. As virtudes são adquiridas na vida pelas experiências, por repetições das mesmas, e inserem na alma inclinações que facilitam a obtenção dos resultados buscados pelas inclinações naturais. Essas virtudes são qualidades que aperfeiçoam, atualizam, as potências da alma às suas inclinações naturais. Assevera o Aquinate: "[...] a virtude [...] torna bom o homem e torna boa a sua obra" (De virtutibus, Q. 5, resp.). Contudo, os vícios (os hábitos maus), ao invés de aperfeiçoarem as inclinações das potências, as depravam.
} 
modo que por determinados meios os atos humanos alcancem seu devido fim" (Post. Anali.. lib. 1, L. I, n. 1).

Ora, a mesma razão que ordena os atos das partes inferiores do homem pode ordenarse a si mesma, ou seu próprio ato, ou seja, a razão reflexiona sobre si mesma, o intelecto intelige a si mesmo. Então, tal como a razão ordena a mão na fabricação de algo, "é necessário que alguma arte dirija o ato mesmo da razão, pelo qual o homem proceda ordenadamente, facilmente e sem erro nesse ato. E esta arte é a lógica, quer dizer, a ciência racional" (Post. Anali.. lib. 1, L. I, n. 2). Eis a definição de Lógica, segundo Tomás de Aquino, nos Analíticos Posteriores.

O ato mesmo da razão é a matéria própria dessa arte que é a Lógica e, além disso, esta é chamada (ciência) racional visto ser segundo a razão - que é comum a todas as artes e ciências. Ademais, o Aquinate a chama de "arte das artes, porque dirige o ato da razão, dos quais procedem todas as demais artes" (Post. Anali.. lib. 1, L. I, n. 2), aproximando-se de como ele a chamava no De Trinitate, de instrumental (mas instrumental das ciências).

A diferença essencial entre as ciências e artes é que aquelas consideram a ordem que as coisas têm por si, por natureza, enquanto estas imprimem ordem em coisas que são passíveis de ordenação. A Lógica pode então tanto considerar a ordem das operações do intelecto (isto faz dela uma ciência) quanto a sua matéria mesma, os atos intelectuais, passíveis de ordenação (o que faz dela uma arte). É a Lógica, então, uma arte-ciência, lato sensu.

É sabido que cada disciplina intelectual é especificada pelo objeto (genus subjectum) - e mesmo pelo método, como se disse anteriormente. Um objeto (ou sujeito) de uma arte ou ciência é aquilo de que a ciência ou arte trata própria e simplesmente, tal como o predicado se diz de um sujeito numa oração. Por isso a necessidade de procurar o objeto da Lógica, a fim de que sua definição seja mais completa. A Lógica se ocupa de uma dificuldade que não é real. Ela se ocupa das ideias/concepções que temos das coisas, tratando estas, então, indiretamente. Essas ideias ou conceitos da realidade tomadas pela Lógica, a Escolástica as chama de segundas intenções, enquanto que as intenções que a Metafísica tem para com a realidade mesma são chamadas de primeiras (intenções). As primeiras intenções são nossos conceitos imediatos da realidade, suas representações primeiras; enquanto as segundas intenções são esses mesmos conceitos em "relações objetivas que eles recebem pelo fato de serem pensados" (GARDEIL, 2013, p. 72). Exemplifique-se com o conceito de animal, considerado como primeira intenção a própria realidade do animal, de sua natureza individual, 
enquanto a segunda intenção designa seu estatuto de ideia universal — gênero dos seres vivos, do qual procedem as mais diversas espécies.

Estabelece-se, assim, o objeto ou sujeito da Lógica, as segundas intenções, ou entes de razão, noutra terminologia escolástica. $\mathrm{O}$ ente de razão ou as segundas intenções só existe no pensamento que o concebe - assim são os raciocínios de privações, negações e relações. Espécie humana não existe enquanto tal, a não ser na inteligência que a concebe. "Não é estranho que uma arte tão importante como a de pensar disponha de elementos de tão pouca consistência ontológica, porque sempre a arte é de uma ordem inferior à natureza”, acrescenta Calderón (2011, p. 138), indicando que a matéria de estudo da Lógica é abstrata. Recorrendo ao Comentário à Metafísica de Aristóteles, o Aquinate diz ser o ente de razão o sujeito da Lógica:

[...] o ente de razão é propriamente o sujeito da lógica. Contudo, tais intenções inteligíveis são equiparadas aos entes da natureza, pois todos os entes da natureza caem sob a consideração da razão. E, por isso, o sujeito da lógica se estende a todas as coisas, sobre as quais se predica o ente da natureza. (AQUINO, 2016, p. 356).

Já se estabeleceu a matéria da Lógica, seu sujeito, e para dar uma definição completa falta situá-la em um gênero. Dos dez gêneros supremos elencados por Aristóteles ${ }^{15}$, a Lógica se encaixa numa certa Qualidade do intelecto. A Qualidade se divide em quatro espécies: hábitos, potências, paixões e figuras. Assim sendo, a Lógica "é um hábito operativo da razão, ou seja, uma disposição permanente da razão que a ajuda a dispor retamente suas operações" (CALDERÓN, 2011, p. 143, tradução nossa). Contudo, a arte "constrói" (ordena) seu sujeito, enquanto a ciência já o encontra pronto. Assim sendo, como a razão ao construir artificialmente algo, uma mesa, por exemplo, dá a esse algo, em razão de seu fím, uma matéria a ser usada e uma forma (artificial), assim a definição de Lógica também considerará sua finalidade e matéria.

A definição de Lógica dada por Tomás de Aquino no seu Comentário aos II Analíticos contempla o dito anteriormente (finalidade e matéria). Ela pertence ao gênero das artes

\footnotetext{
15 Substância (gênero máximo) — todas as outras são propriedades ou acidentes desta primeira —, quantidade, qualidade, relação, ubiquação (lugar/onde), quando (tempo), situação (posição), posse (hábito), ação e paixão. (ARISTÓTELES, Órganon (I - Categorias/ II Periérmeneias), 1985, p. 47).
} 
(qualidade/hábito intelectual), sua matéria é o ato mesmo da razão ${ }^{16}$ e sua finalidade é que a mesma razão proceda ordenadamente, com facilidade e sem erro.

Descobertos o sujeito (entes de razão ou segundas intenções, ou ainda universalidade lógica), a matéria (atos da razão) e a finalidade (ordenação, facilidade e sem erro) da Lógica podemos dar-lhe uma definição mais completa: “É a arte diretiva do próprio ato da razão (matéria) segundo as regras da universalidade (sujeito), para que o homem alcance a ciência ordenada, facilmente e sem erro (finalidade)." (CALDERÓN, 2011, p. 146, tradução nossa).

\subsection{A divisão da lógica}

Da mesma forma como os atos da razão se dividem, a Lógica se divide em partes. O Aquinate (STh. II-II, q. 48 art. único ) elenca três tipos de partes com relação ao todo: integrais, subjetivas e potenciais.

As partes integrais são como os alicerces, paredes e teto que constituem uma casa, ou as cordas, "braço" e tarraxas em um violão — se falta uma dessas partes, o todo fica comprometido, e ainda não se pode tomar uma dessas partes pelo todo. Se dizemos, por exemplo, que "temos um teto para morar", é num sentido metafórico, numa analogia de proporcionalidade imprópria ${ }^{17}$. As partes subjetivas são como o leão e o boi fazendo parte da espécie animal, que seria um todo universal; aqui tem-se uma atribuição unívoca ${ }^{18}$. As partes potenciais são como o nutritivo, sensitivo e o racional; assim, a alma é um todo potencial. Essas três partes são humanas, mas a parte racional é mais que as outras duas. Tem-se aqui uma analogia própria ${ }^{19}$.

Os atos da razão são três, dois considerados enquanto intelecto e um enquanto próprio da razão:

1) A primeira operação do Intelecto é a inteligência dos indivisíveis ou incomplexos, ou ainda, como é chamada na escola tomista, simples apreensão — nesta operação concebe-se o que uma coisa é, se captam ou abstraem noções simples (essência) como homem, branco,

\footnotetext{
${ }^{16}$ Estes atos da razão, matéria da Lógica, são as três operações do intelecto: $1^{\mathrm{a}}$ operação — simples apreensão, pela qual se obtêm as essências universais (estudada por Aristóteles nas Categorias); $2^{\mathrm{a}}$ operação — o juízo ou composição, pela qual se formam as proposições (Perihermeneias); $3^{\mathrm{a}}$ operação - o raciocínio, pelo qual se constroem os argumentos e demonstrações silogístico-científicas (I e II Analíticos) (CALDERÓN, 2011, p 133). ${ }^{17}$ Quando se aplica um conceito acidentalmente a um semelhante inferior.

${ }^{18}$ Um termo unívoco é o que designa uma essência cujas notas se realizam plena e igualmente em seus inferiores. No exemplo dado, animal se aplica tanto ao leão quanto ao boi.

${ }^{19}$ Quando o conceito se realiza nos inferiores segundo a mesma definição. Assim, no exemplo dado, o homem é cada uma de suas partes.
} 
quadrúpede (GARDEIL, 2013, p. 74). Aristóteles a estuda na obra As Categorias ou Predicamentos (Post. Analit. L. I, Proêmio).

2) A segunda operação do Intelecto é a composição e divisão, ou juízo — aqui se dá o verdadeiro e o falso, o afirmativo e negativo por meio de uma oração com sujeito, cópula e predicado, ou nome, verbo e qualidades (GARDEIL, 2013, p. 74). Aristóteles ensina isso em sua obra Sobre a Interpretação (Peri hermeneias) conforme recorda o Aquinate (Post. Analit. L. I, Proêmio).

\begin{abstract}
Os sons emitidos pela fala são símbolos das paixões da alma, ao passo que os caracteres escritos (formando palavras) são os símbolos dos sons emitidos pela fala. Como a escrita, também a fala não é a mesma em toda parte [...]. Entretanto, as paixões da alma, elas mesmas, das quais esses sons e caracteres escritos (palavras) são originalmente signos, são as mesmas em toda parte, como o são os objetos das quais essas paixões são representações ou imagens. (Sobre a Interpretação, I, 16a1, 5).
\end{abstract}

Nessa passagem o Estagirita propõe três coisas, através das quais uma quarta é conhecida: palavras escritas, palavras orais e paixões da alma, e mediante esta se conhecem as coisas. As palavras escritas e orais não são, segundo o filósofo grego, representações diretas das coisas, mas o são das paixões da alma. Ou seja, as paixões da alma são representações diretas da realidade extra mental, mediante as quais se dão as palavras orais e escritas. Às paixões o Filósofo dá o nome de imagem ${ }^{20}$.

Noutras palavras, as coisas, a realidade (cuja existência é independente de nosso intelecto), provocam no intelecto humano paixões, quer dizer, este intelecto recebe, sofre influxo das coisas. A essas paixões chama-se imagem sensível. Esta imagem sensível é formada através da experiência dos cinco sentidos externos (tato, paladar, audição, visão e olfato), unificados no senso comum, e produzida pela imaginação ${ }^{21}$. A partir dessa imagem sensível, o intelecto, em sua primeira operação, produz uma imagem intelectual, um conceito imaterial — por exemplo: homem, substância vivente animal racional — através da abstração $^{22}$, que prescinde os acidentes da imagem sensível, ficando somente com o essencial desta. Isto posto, continua o Estagirita:

\footnotetext{
20 "Imago se forma por sincope de imitago, que vem de imitar. Com a raiz im se forma similis". (CALDERÓN, 2011, p. 50).

${ }^{21}$ Ambos são dois dos quatro sentidos internos. Os outros dois são a memória e a cogitativa (no homem) ou estimativa (nos animais brutos).

${ }_{22}$ Abstrair, que vem de abs-trahere, significa trazer desde (CALDERÓN, 2011, p. 51).
} 
Como por vezes assomam pensamentos em nossas almas desacompanhados da verdade ou da falsidade, enquanto assomam por vezes outros que necessariamente encerram uma ou outra, coisa idêntica ocorre em nossa linguagem, uma vez que a combinação e a divisão são essenciais para que se tenham a verdade e a falsidade. Um nome ou um verbo por si mesmo muito se assemelha a um conceito ou pensamento que não é combinado nem dividido. Tal é o caso de homem, por exemplo, ou branco, se enunciados sem qualquer acréscimo. Não é verdadeiro nem falso [...] (Categorias, I, 16a1, 10-15).

A verdade está, pois, na segunda operação do intelecto, que supõe a primeira operação e sua obra (o conceito quiditativo). Ela é certa relação $o^{23}$ entre a coisa (realidade) e o intelecto. E é uma relação dupla: uma coisa (obra de arte, por exemplo) é verdadeira se é como se pensa (o seu autor), e o ato do intelecto (juízo) é verdadeiro se se pensa a coisa tal como ela é. Daí a ampla definição medieval para a questão "Quid est veritas?" (O que é a verdade): Adequatio rei et intelecto (adequação entre coisa e intelecto). Por isso, do ângulo da coisa se diz: adequação da coisa ao intelecto (adequatio rei ad intelectum); e do ângulo do intelecto: adequação do intelecto à coisa (intelectus ad rem) (CALDERÓN, 2011, p. 64).

Verdadeiro se diz do intelecto quando: 1) ele se adequa, pelo conceito, na $1^{\mathrm{a}}$ Operação, se assemelhando à coisa inteligida; 2) ao se julgar a si mesmo - 2a Operação; 3) por consequência da anterior, uma proposição corresponda à realidade significada.

$\mathrm{O}$ ato de afirmar ou negar tem por obra a enunciação (mental), que tem na escrita a expressão desse juízo. Os elementos lógico-gramaticais da enunciação são o sujeito, a cópula e o predicado. Sujeito e predicado são os elementos materiais da enunciação, enquanto o verbo de cópula seria, analogamente, como que a forma que determina a matéria. A primeira operação do intelecto busca alcançar a essência da coisa, enquanto a segunda operação considera a sua existência, pelo juízo, que a nega ou afirma (GARDEIL, 2013, p. 119-120).

As enunciações podem ser simples, compostas e modais. Estas últimas são quando o predicado é o mesmo modo de ligação entre dois termos num juízo, por exemplo: “é necessário que o justo seja recompensado" (GARDEIL, 2013, p. 127). Esses modos são o impossível, o possível, o necessário e o contingente, e afetam o verbo de cópula. Se a modalidade afetasse somente o predicado ou o sujeito, isoladamente, — "foi-nos proposto um problema impossível” (GARDEIL, 2013, p. 132) — não haveria verdadeiro modal.

Os enunciados modais de futuros contingentes são aqueles que podem ou não existir (no futuro), logo, a verdade ou falsidade nessas proposições não se as tem de antemão, como se teria na enunciação "Napoleão morreu em Santa Helena" (GARDEIL, 2013, p. 140). O

\footnotetext{
${ }^{23}$ Uma das categorias, segundo Aristóteles.
} 
exemplo aristotélico, comentado por Aquino ${ }^{24}$ da batalha naval é conhecido: "haverá uma batalha naval amanhã", e sua oposta, "não haverá uma batalha naval amanhã" — se dissermos que a primeira é verdade já não será um evento contingente, mas necessário. Nem uma nem outra, isoladamente, pode ser dita verdadeira ou falsa, visto que se contradizem mutuamente.

3) A terceira operação do Intelecto, esta enquanto o que é próprio da razão, é o raciocínio, isto é, discorrer de um para outro; de uma verdade conhecida a uma desconhecida (GARDEIL, 2013, p. 75). Desse ato da razão se ocupam os demais livros lógicos ${ }^{25}$ do Estagirita, conforme explicita o Aquinate (Post. Analit. L. I, Proêmio).

Isto posto, considera-se a Lógica um todo integral cujas partes (as mesmas três operações) integrais são as supracitadas operações.

É famosa a frase aristotélica, que Aquino toma como sua: "a arte imita a natureza" (Post. Analit. L. I, Proêmio). Com isso ele quer indicar que da mesma forma como na natureza as coisas se dão de três modos — algumas vezes a natureza age ou produz por necessidade, sem falhas; às vezes ela age sem falhas, mas podendo falhar (como quando do sémen se gera um animal perfeito); às vezes ela falha no que não deveria falhar (como quando de um sémen se gera um monstro, um animal defeituoso) — assim também se dão os atos da razão, os quais a Lógica ordena.

Há um processo racional que induz a necessidade, em que faltar à verdade é impossível; este processo garante certeza à ciência. A esse processo dá-se o nome de judicativa, pois o juízo opera a partir da certeza da ciência, e essa certeza acontece por resolução nos primeiros princípios, por isso esse processo também é dito analítico ou resolução. A certeza advinda da Resolução vem da forma do silogismo, estudada nos Primeiros Analíticos, ou pela matéria do silogismo demonstrativo, estudada nos Segundos Analíticos ${ }^{26}$. Há outro processo: segundo o Aquinate, é o caso da maioria dos atos racionais, no qual se chega à verdade, mas sem necessidade. A esse processo dá-se o nome de invenção, pois a busca nem sempre se dá com certeza. O que for descoberto aqui neste processo precisará submeter-se ao processo da judicativa para alcançar certeza, visto que seja uma crença ou opinião provável. Quando a razão se inclina a uma parte da crença ou opinião (constituídas de contradição) há o silogismo dialético, sobre o qual trata os Tópicos de

\footnotetext{
${ }^{24}$ Cf. Categorias, L 1, lect. 13, 1-12.

${ }^{25}$ Isto é, os Analíticos anteriores e posteriores, Tópicos, Retórica, Poética, e Refutações Sofísticas. Abrange-se, nessa divisão da Lógica, todo o Órganon aristotélico.

${ }^{26}$ Esse tipo de silogismo (o demonstrativo ou científico) pertence ao que hodiernamente chama-se epistemologia (CALDERÓN, 2011, p. 85).
} 
Aristóteles. E se, na invenção, não surge nem uma crença ou opinião, mas uma suspeita da verdade, aí se ordena o estudo da Retórica. E quando a invenção é como que movida por alguma representação para que alcance alguma parte da contradição, a isso se ordena a Poética.

Considera-se a divisão do parágrafo anterior como sendo a Lógica um todo potencial, cujas partes potenciais são: a Dialética, arte que busca a opinião mais provável; a Retórica, que faz propender ao verossímil, e se afastar do inverossímil; e a Poética, que faz propender ao verdadeiro mediante o belo.

E há um terceiro processo racional, no qual a razão fracassa na busca pela "verdade por defeito de algum princípio que devia observar-se no raciocínio" (Post. Analit. L. I, Proêmio). Esse processo é estudado pela parte da Lógica chamada sofística, tratada na obra Refutações sofísticas. Mas a arte e a ciência são hábitos intelectuais, virtudes. Ora, a finalidade da Sofística é má - fazer o falso se passar por verdadeiro; logo não é arte, nem virtude, mas vício (um vício intelectual).

\section{A SUBALTERNAÇÃO DAS CIÊNCIAS E A ORDEM DAS DISCIPLINAS}

Retome-se o Comentário de Tomás de Aquino ao De Trinitate de Boécio, especificamente a resposta ao $5^{\circ}$ argumento inicial do artigo 1, Questão 5, e o Comentário aos Analíticos Posteriores, Livro I, cap. 25, para esclarecer como as ciências se relacionam.

O Aquinate divide a relação das ciências de dois modos:

[...] uma ciência está compreendida sob uma outra de duas maneiras: de um modo, como sua parte, isto é, quando seu sujeito é uma parte do sujeito desta, como a planta é uma parte do corpo natural; daí também a ciência das plantas está compreendida, como uma parte, sob a ciência natural (Física); de outro modo, uma ciência está compreendida sob uma outra como subalternada a ela, isto é, quando na ciência superior determina-se o porquê daquilo de que na ciência inferior só se conhece o quê, assim como a música está colocada sob a aritmética. [...] (Super Boetii, Q.5, a. 1, ad 5, grifos nossos ).

Essa divisão se atém ao ponto de vista do objeto de cada ciência e também no modo de proceder das ciências. Do ponto de vista do objeto, deve-se distinguir uma parte específica, derivada por "acréscimo de uma diferença acidental ao gênero sujeito da ciência subalternante" (NASCIMENTO, in AQUINO, 1999, p. 24). Assim, por exemplo, acrescentando a diferença sonoro ao número (objeto da aritmética, teríamos número sonoro, 
ou seja, o gênero sujeito da música (NASCIMENTO, in AQUINO, 1999, p. 24). Do ponto de vista do modo de proceder, ou dos tipos de explicação, a ciência subalternante explica a causa (o porquê) daquilo que se conhece (o quê) numa ciência subalternada.

Isso é corroborado no Comentário aos Analíticos Posteriores:

[...] é preciso entender que uma ciência está sob a outra de duas maneiras. De um primeiro modo, quando o sujeito de uma ciência é uma espécie do sujeito de uma ciência superior, assim como o animal é uma espécie do corpo natural. De outro modo, quando o sujeito da ciência inferior não é uma espécie do sujeito da ciência superior; mas o sujeito da ciência inferior se compara ao sujeito da superior como o material em relação ao formal. (Post. Anali. L 1, cap.25, 2).

Interessante notar que quanto mais uma ciência está próxima do sensível mais ela se aplica ao $o q u \hat{e}^{27}$, e o porquê $\hat{e}^{28}$ é explicado pelas ciências que se afastam da sensibilidade, como a matemática e a metafísica: "[...] cabe aos sensíveis, isto é, às ciências inferiores que aplicam ao sensível conhecer o quê; mas saber o porquê cabe aos matemáticos, isto é, às ciências cujos princípios são aplicados ao sensível” (Post. Anali. L I, cap. 25, 4).

\subsection{O exemplo da subalternação da gramática à lógica}

Por conta da natureza social-política do homem — decorrente de sua racionalidade — este é capaz de comunicar seus pensamentos. Se o homem fosse um animal solitário, bastaria que as concepções mentais que ele tem se conformassem com a realidade ou a refletissem, e assim ele conhecesse esta (AQUINO, 2018, p. 49). Mas, como dito, ele é um ser social, e se comunica. Para manifestar seus pensamentos a lugares e tempos distintos do aqui e agora, em virtude de seu conhecimento intelectual, o homem usa da linguagem (AQUINO, 2018, p. 49). Numa certa ordem poder-se-ia dizer que a escrita é signo da fala, a fala por sua vez é signo das nossas concepções mentais, e estas são como que imagens da realidade, doutrina exposta anteriormente, conforme o Da Interpretação, de Aristóteles.

A arte que ordena a fala é a Linguagem, que reflete indiretamente a própria realidade. Assim as classes de palavras expressam de alguma maneira as dez categorias ou gêneros máximos do ente, segundo Aristóteles: o substantivo exprime as substâncias; o adjetivo corresponde à qualidade, relação, situação, posse, entre outros; o verbo expressa a ação, paixão e posse (também); o advérbio se aplica ao tempo e lugar.

\footnotetext{
${ }^{27}$ Quer dizer, a responder o que a coisa é.

28 A causa.
} 
Note-se no seguinte exemplo essas dez categorias, para o qual podem-se aplicar as chamadas classes gramaticais:

\begin{abstract}
Olhe-se para qualquer homem, que é uma substância assim como o é qualquer cisne ou qualquer laranjeira, e constatar-se-á, por exemplo, que mede $\mathrm{x}$ e pesa y (quantidade); que é branco ou negro (qualidade); que é pai ou filho de alguém (relação); que ocupa um lugar (ubiquação); que se encontra em determinado instante (quando); que está de pé ou sentado (situação); que vai armado ou calçado (habitus); que caminha ou toca um trompete (ação); e que é molhado pela chuva ou queimado pelo sol (paixão). (NOUGUÉ, 2015, p. 36).
\end{abstract}

Graças ao conhecimento intelectual o homem busca comunicar seu pensamento para o distante e o futuro, e isso se dá pela escrita. Para reger a escrita é necessária uma arte, a Gramática. A definição desta se dá, assim como na Lógica, pelo seu sujeito, matéria e fim: as formas linguísticas e suas relações sintáticas formais (sujeito), o ato mesmo da escrita (matéria) e a comunicação no espaço e tempo (fim): “A Gramática é a arte diretiva da escrita segundo regras morfossintáticas cultas, para que o homem possa transmitir suas concepções e argumentações com ordem, com facilidade e sem erro a outros homens distantes no espaço e no tempo." (NOUGUÉ, 2015, p. 47).

A Gramática está subalternada à Lógica, pois aquela rege a escrita, que é signo das concepções da razão, cuja arte é a mesma Lógica. Assim como a Gramática está para a escrita, a Lógica está para a razão. Muitas terminologias usadas em Gramática advêm da Lógica, e o entendimento mesmo desses termos, por exemplo a oração, sua divisão essencial em sujeito e predicado, o que se entende por nome e verbo, entre outras noções, foram tratadas no Peri hermeneias de Aristóteles, o qual foi comentado por Tomás de Aquino.

Como a Lógica se aplica na Gramática? Por meio de reduções analógicas, ou seja, pela aplicação de certos princípios da Lógica numa normativa ou padrão convencional. Exemplo se tem no caso da separação por vírgula de sujeito e predicado: a Lógica diz que estes são termos essenciais de uma oração perfeita, sujeito é aquilo a que se aplica um predicado, e este é aquilo que se atribui a um sujeito; sem verbo não há predicado; a vírgula se usa para separar termos que sintaticamente devem se separar, pausas e evitar anfibologia; assim não se separa sujeito e predicado com vírgula (NOUGUÉ, 2015, p. 51). Imediatamente a Gramática serve à linguagem como um todo, em sua manutenção e aprimoramento; e, mediatamente, ela serve ao pensamento, logo à sua arte, a Lógica, e esta serve à Ciência, como dito anteriormente. 


\section{2 A ordem das disciplinas}

Existe, diante de todo o estudado até aqui, uma ordem para o estudo das ciências. Essa ordem é dupla: a do mais cognoscível em si (naturaliter), e a do mais cognoscível para nós (quod nos), portanto, uma ordem ontológica e outra pedagógica (NASCIMENTO, in AQUINO, 1999, p. 25).

Sobre o início da ordem ontológica, diz o Aquinate: “[...], é preciso dizer que, ainda que a ciência divina seja naturalmente a primeira de todas as ciências, em relação a nós, as outras ciências são anteriores" (Super Boetii Q. 5, a. 1, ad 9). Todas as ciências tomam uma parte do ente - objeto da Metafísica - para considerá-lo de um modo distinto e específico (Super Boetii Q. 5, a. 1, ad 6); tem-se assim, com a Metafísica, o início da ordem ontológica do aprendizado das artes-ciências, ou o término da ordem pedagógica, pois “é a última em relação a nós" (Super Boetii Q. 5, a. 1, ad 9). Para começar a ordem pedagógica deve-se primar pelas ciências que são mais conhecidas em relação a nós, como a ciência natural (Física) (Super Boetii Q. 5, a. 1, ad 9); por isso esta estaria, na mesma ordem pedagógica, antes da Metafísica.

A pedagogia medieval do Trívium, composto pela Gramática e pela Lógica (e aqui há algumas variações, entre os autores e comentadores, entre Retórica, Dialética ou Lógica), e do Quadrívium (Aritimética, Geometria, Música e Astronomia) foi estabelecida nessa ordem pedagógica aludida acima - começando pelo mais cognoscível a nós - preparando o intelecto aos temas filosóficos posteriores - mais cognoscíveis em si: as disciplinas do agere (Ética, Política e Economia), seguidas pelas disciplinas especulativas (Física, Matemática e Metafísica) e, por fim, a Teologia Sagrada.

\section{CONSIDERAÇÕES FINAIS}

Um dos problemas da herança filosófica de Tomás de Aquino é a não sistematização da sua mesma filosofia, que se encontra espalhada em vastos tratados de cunho teológico (Teologia Revelada ou Sagrada). Não que recolher as pérolas de sua filosofia seja tarefa impossível, mas consigna-se que é um árduo trabalho, e gratificante até, por produzir muitas discussões interessantes. Testemunha disso é o comentário que aqui se analisou, no item 1, de cunho eminentemente teológico, sobre o dogma da Santíssima Trindade, mas que na Questão 5 tem toda uma organização sobre os objetos de cada ciência teorética, sobre o lugar e a 
importância da Lógica, e na Questão 6 uma extensa tratativa sobre o modo de proceder de cada ciência, modos estes estritamente ligados à Lógica.

Fica o dever aos comentadores, tradutores e demais interessados de desenvolver e sistematizar a filosofia do Aquinate. Esse dever não pode deixar de atentar-se às obras de cunho estritamente filosóficas - sim, elas existem e são substanciais, como por exemplo os vários Comentários às obras aristotélicas (à Política, à Física, à Ética, aos Analíticos Posteriores, entre outros), e as sua obras de juventude (como Princípios da natureza, O ente e a essência, e outras). Mormente, muitos assuntos estão imbricados uns com os outros, por isso vemos a necessidade de uma sistematização. Nota-se nos temas aqui tratados: da metafísica à física, desta à lógica, passando pela matemática e pelos modos de conhecimento e operações do intelecto - é Teoria do Conhecimento e Lógica envoltas nas discussões das ciências teoréticas - Física, Matemática e Metafísica. A proposta do Trivium (e do Quadrívium) segue uma necessidade pedagógica para desenvolver o intelecto humano com ordem na aquisição das ciências. Mas mesmo o Trivium necessita de uma revisão, conforme o mesmo Aquinate declara: “[...] as sete artes liberais não dividem de maneira suficiente a filosofia teórica" (Super Boetii, Q. 5, a. 1, ad 3). Essa revisão poderá fundamentar uma Epistemologia das Virtudes, haja vista a profunda ligação entre o conhecimento humano e as virtudes intelectuais teóricas e práticas, conforme exposto no item 2.

Em suma, pode-se dizer que a Lógica é uma arte-ciência em sentido lato; ciência redutivamente, porquanto considera a ordem e o resultado das operações do intelecto, e arte, também redutivamente, quando produz e ordena essas mesmas operações do intelecto. Ademais, seu aprendizado está, numa ordem pedagógica, logo no início das outras artes e ciências.

\section{REFERÊNCIAS}

AQUINO, T. de. Comentário ao Tratado da Trindade de Boécio: Questões 5 e 6. Tradução de Carlos Arthur R. do Nascimento. São Paulo: Fundação Editora da UNESP, 1999.

AQUINO, T. de. Comentário à Metafísica de Aristóteles, v. 1 (Livros I-IV). Tradução de Paulo Faitanin e Bernardo Veiga. Campinas: Vide Editorial, 2016.

AQUINO, T. de. Comentario de los Analíticos Posteriores de Aristóteles. Tradução de Ana Mallea y Marta Daneri Rebok. Navarra, Espanha: EUNSA, 2002.

AQUINO, T. de. Comentário ao Sobre a Interpretação de Aristóteles. Tradução de Paulo Faitanin e Bernardo Veiga. Campinas: Vide Editorial, 2018.

AQUINO, T. de. Suma teológica. Tradução de Alexandre Correia. v. 2 e 3. 4. ed. Campinas: Editora Permanência \& Ecclesiae, 2016. 
ARISTÓTELES. Metafísica. Ensaio introdutório, texto grego com tradução e comentário por Giovanni Reale. Tradução de Marcelo Perine. vol. 2. São Paulo: Loyola, 2002.

ARISTÓTELES. Órganon (I - Categorias/ II Periérmeneias). Tradução de Pinharanda Gomes. Lisboa-Portugal: Guimarães Editora, 1985.

CALDERÓN A. Umbrales de la filosofia: cuatro introducciones tomistas. Moreno: el autor, 2011.

GARDEIL, Henri-Dominique. Iniciação à filosofia de São Tomás de Aquino: introdução, lógica e cosmologia. Tradução Cristiane N. A. Ayoub e Carlos E. de Oliveira. São Paulo: Paulus, 2013.

NOUGUÉ, Carlos. Suma gramatical da língua portuguesa: gramática geral e avançada. São Paulo: É-Realizações, 2015. 